\title{
Special Issue on Fracture and Fatigue Assessments of Structural Components
}

\author{
Alberto Campagnolo \\ Department of Industrial Engineering, University of Padova, Via Venezia 1, 35131 Padova, Italy; \\ alberto.campagnolo@unipd.it; Tel.: +39-049-827-7475
}

Received: 4 August 2020; Accepted: 24 August 2020; Published: 11 September 2020

\begin{abstract}
This Special Issue covers the broad topic of structural integrity of components subjected to either static or fatigue loading conditions, and it is concerned with the modelling, assessment and reliability of components of any scale. Dealing with fracture and fatigue assessments of structural elements, different approaches are available in the literature. They are usually divided into three subgroups: stress-based, strain-based and energy-based criteria. Typical applications include materials exhibiting either linear-elastic or elasto-plastic behaviours, and plain and notched or cracked components subjected to static or cyclic loading conditions. In particular, the articles contained in this issue concentrate on the mechanics of fracture and fatigue in relation to structural elements from nano- to full-scale and on the applications of advanced approaches for fracture and fatigue life predictions under complex geometries or loading conditions.
\end{abstract}

Keywords: fracture; fatigue; notch; crack; metal; structure; welded joint; FEM

\section{Introduction}

This Special Issue was introduced to collect the latest research on fracture and fatigue of structural elements, and more importantly, to address present challenging issues in the context of the integrity of structures from nano- to full-scale and components under complex loading conditions. In light of the above, this Special Issue embraces interdisciplinary works aimed at understanding and deploying physics of fatigue and failure phenomena, advanced experimental and theoretical failure analysis, modelling of the structural response with respect to both local and global failures, and providing structural design approaches to prevent engineering failures. Original contributions from engineers, mechanical and material scientists, computer scientists, physicists, chemists, and mathematicians are presented, following both experimental, numerical and theoretical approaches. There were 34 papers submitted to this Special Issue, and 11 papers were accepted (i.e., 33\% acceptance rate).

\section{Fracture}

A number of papers in this Special Issue are specifically devoted to fracture mechanics problems [1-3]. Different approaches have been adopted, including experimental investigations, theoretical models, and numerical simulations.

Gallo and Sapora [1] have proposed a method which could be useful for predicting the static failure of micro- and nano-electromechanical systems (MEMS, NEMS). In more detail, the authors have applied a coupled stress-energy approach—so-called Finite Fracture Mechanics—-to predict the failure load of notched nano-components made of single crystal silicon.

In [2], the authors developed a two-dimensional ordinary state-based peridynamic modeling of mode-I delamination growth in a double cantilever composite beam test using revised energy-based failure criteria. The proposed analytical model has successfully been validated against experimental results. 
Finally, in [3], a stress field analytical model of the wellbore coal rock has been established by considering the irregularity of the cleat distribution and the influence of the cleat filler. The analytical model has been compared with numerical simulations obtaining a good agreement.

\section{Fatigue}

In this Special Issue, the fatigue phenomenon has been investigated from experimental, numerical, and theoretical points-of-view in different papers [4-11]. Contributions [4-8] were focused on the application of advanced analytical or numerical approaches to predict the experimental fatigue strength of laboratory specimens; while, on the other hand, papers [9-11] were mainly devoted to the fatigue assessment of full-scale, real structures undergoing complex loading conditions.

Ronchei and co-authors [4], have applied a critical plane-based multiaxial fatigue criterion for the fatigue life assessment of Ti-6Al-4V notched specimens. The accuracy of the proposed criterion has successfully been evaluated through experimental data available in the literature.

In [5], the authors proposed an energy-based approach for the fatigue life estimation of welded joints through thermal-graphic measurement. A model based on intrinsic energy dissipation was applied to high strength steel welded joints showing a good agreement between estimations and experimental results.

Paper [6] was devoted to presenting a multiscale fatigue damage evolution model for describing both the mesoscopic voids propagation and fatigue damage evolution process, reflecting the progressive degradation of metal components in the macro-scale. A method of defect classification was employed to implement 3D reconstruction technology based on the micro-computed tomography scanning damage data with FE simulations. The predictions were validated through a comparison with experimental data.

The aim of [7] was to characterize the propagation of fatigue cracks using the damage index derived by various acoustic features of ultrasonic guided waves. The method has been validated by monitoring the fatigue crack propagation in a steel plate-like structure.

In [8], the authors have formulated a numerical model to simulate the thorough failure process on concrete, ranging from microcracks growth, crack coalescence, macrocrack formation and propagation, to the final rupture. The model has been applied to simulate the fatigue rupture of three-point bending concrete beams, observing a good agreement between numerical results and experimental observations available in literature.

Paper [9] focused on the assessment of fatigue life and characterization of the fatigue crack behavior of an aluminum scroll compressor, taking into account both mean stress effects and elastic-plastic behavior of the material. The authors took advantage of both analytical and numerical models.

In [10], the authors have investigated the factors inducing fatigue crack initiation from the positioning block weld toe of metro bogie frame, which is the critical safety part of the urban metro vehicle. Metallographic analyses were employed to study the failure modes and fracture characteristics of the weld toe of positioning block. On-track testing was carried out to obtain acceleration and the stress response information of the bogie, and to investigate which factors could be optimized in order to reduce the failure probability.

Finally, the aim of [11] was to develop a master-slave model with fluid-thermo-structure interaction for the thermal fatigue life prediction of a thermal barrier coat in a nozzle guide vane. The master-slave model integrates the phenomenological life model, multilinear kinematic hardening model, fully coupling thermal-elastic element model, and volume element intersection mapping algorithm to improve the prediction precision of thermal fatigue life.

Funding: This research received no external funding.

Acknowledgments: This Special Issue would not have been made possible without the irreplaceable contributions of valuable authors coming from many different countries, hardworking and professional reviewers, and dedicated editorial team of Applied Sciences, an international, peer-reviewed journal that is free for readers embracing all aspects of applied sciences. I would like to take this opportunity to record my sincere gratefulness to all reviewers. 
Finally, I place on record my gratitude to the editorial team of Applied Sciences, and special thanks to Daria Shi, Managing Editor, from MDPI Branch Office, Beijing.

Conflicts of Interest: The author declares no conflict of interest.

\section{References}

1. Gallo, P.; Sapora, A. Brittle failure of nanoscale notched silicon cantilevers: A finite fracture mechanics approach. Appl. Sci. 2020, 10, 1640. [CrossRef]

2. Jiang, X.-W.; Guo, S.; Li, H.; Wang, H. Peridynamic modeling of mode-i delamination growth in double cantilever composite beam test: A two-dimensional modeling using revised energy-based failure criteria. Appl. Sci. 2019, 9, 656. [CrossRef]

3. Zhao, X.; Wang, J.; Mei, Y. Analytical model of wellbore stability of fractured coal seam considering the effect of cleat filler and analysis of influencing factors. Appl. Sci. 2020, 10, 1169. [CrossRef]

4. Ronchei, C.; Carpinteri, A.; Vantadori, S. Energy concepts and critical plane for fatigue assessment of Ti-6Al-4V notched specimens. Appl. Sci. 2019, 9, 2163. [CrossRef]

5. Mi, C.; Li, W.; Xiao, X.; Berto, F. An energy-based approach for fatigue life estimation of welded joints without residual stress through thermal-graphic measurement. Appl. Sci. 2019, 9, 397. [CrossRef]

6. Bao, Y.; Yang, Y.; Chen, H.; Li, Y.; Shen, J.; Yang, S. Multiscale damage evolution analysis of aluminum alloy based on defect visualization. Appl. Sci. 2019, 9, 5251. [CrossRef]

7. Jin, H.; Yan, J.; Li, W.; Qing, X. Monitoring of fatigue crack propagation by damage index of ultrasonic guided waves calculated by various acoustic features. Appl. Sci. 2019, 9, 4254. [CrossRef]

8. Wu, B.; Li, Z.; Tang, K.; Wang, K. Microscopic multiple fatigue crack simulation and macroscopic damage evolution of concrete beam. Appl. Sci. 2019, 9, 4664. [CrossRef]

9. Park, S.-Y.; Lee, J.; Heo, J.-T.; Lee, G.B.; Kim, H.H.; Choi, B.-H. Assessment of fatigue lifetime and characterization of fatigue crack behavior of aluminium scroll compressor using C-specimen. Appl. Sci. 2020, 10, 3226. [CrossRef]

10. Wang, W.; Bai, J.; Wu, S.; Zheng, J.; Zhou, P. Experimental investigations on the effects of fatigue crack in urban metro welded bogie frame. Appl. Sci. 2020, 10, 1537. [CrossRef]

11. Guan, P.; Ai, Y.; Fei, C.; Yao, Y. Thermal fatigue life prediction of thermal barrier coat on nozzle guide vane via master-Slave model. Appl. Sci. 2019, 9, 4357. [CrossRef] 